
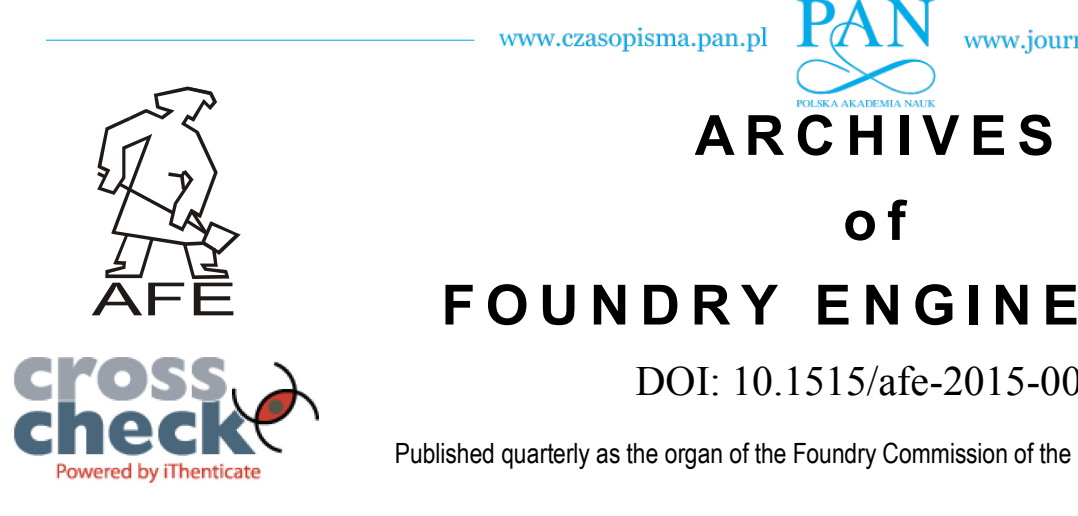

ARCHIVES

FOUNDRY ENGINEERING

DOI: $10.1515 /$ afe-2015-0018

SSN (2299-2944)

Volume 15

Issue $1 / 2015$

\title{
Abrasive Wear of Alloyed Cast Steels Applied for Heavy Machinery
}

\author{
A. Studnicki*, M. Kondracki, J. Suchoń, J. Szajnar, D. Bartocha, T. Wróbel \\ Department of Foundry, Silesian University of Technology, Towarowa 7, 44-100 Gliwice, Poland \\ *Corresponding author. E-mail address: andrzej.studnicki@polsl.pl
}

Received 10.07.2014; accepted in revised form 22.07.2014

\begin{abstract}
In the paper the results and analysis of abrasive wear studies were shown for two grades of cast steels: low-alloyed cast steel applied for heavy machinery parts such as housing, covers etc. and chromium cast steels applied for kinetic nodes of pin-sleeve type. Studies were performed using the modified in Department of Foundry pin-on-disc method.
\end{abstract}

Keywords: Low-alloyed cast steel, Chromium cast steel, Abrasive wear, Pin-on-disc method

\section{Introduction}

Materials applied for manufacturing of contemporary heavy machines need to fulfil the demand of high operational properties and in many cases need to be characterised by high resistance to different kind of wear [1-6].

Low-alloyed cast steels belong to a very wide range of iron alloys used for responsible heavy-loaded elements and parts [514]. They have found many applications in mechanical engineering, including heavy-duty machines for mining and power engineering (mining machines, crushers, loaders, mills etc.). Such cast elements are mainly manufactured using finestructured cast steels derived from American Patent for armour steel, eg. HY-100 or T1 grade.

In the Department of Foundry of Silesian University of Technology efforts were put to applied the low-alloyed cast steel of L20HGSNM grade for elements of heavy mining machine elements. This alloy originates from the group of cast steel resistant to abrasive wear [5] and is characterised with high mechanical strength $(\mathrm{Rm}>1300 \mathrm{MPa}, \mathrm{Re}>1100 \mathrm{MPa})$ and rather low plasticity $(\mathrm{A} 5=6 \%$ ). Such approach required modification of chemical composition and technology of this alloy to improve the plastic properties.
Pins and sleeves in kinetic nodes of heavy machinery work under high and changing loads, very often in conditions of high salinity and dust concentration. In the mining machine the kinetic node between the housing and the working arm is exposed to such conditions, what causes high corrosive and abrasive wear of its elements. In the Department of Foundry of Silesian University of Technology, after analysis of material parameters different cast steel groups, the attention was directed toward the tool cast steels, especially chromium cast steel.

In presented work the results of abrasive wear for elaborated low-alloyed and chromium cast steels were described. The alloys were prepared in laboratory and industrial conditions.

\section{Materials and studies methodology}

Abrasive tests were performed for low-alloyed cast steel prepared in laboratory conditions ( $\mathrm{K} 4, \mathrm{~K} 6$ and $\mathrm{K} 7$ alloys) and in industrial conditions (KL alloy). In case of chromium cast steels the: T6, T7, T8 alloys were prepared in laboratory and TZ1 alloy - in industrial conditions.

For laboratory test the $20 \mathrm{~kg}$ inductive furnace was used with neutral lining applied. After reaching the required temperature of 
liquid cast steel $\left(1600{ }^{\circ} \mathrm{C}\right.$ for low-alloyed and $1550{ }^{\circ} \mathrm{C}$ for chromium cast steel) deoxidation was performed using the FeSi75 master alloy and aluminium. After deoxidation and argon treatment the FeTi and $\mathrm{FeV}$ inoculants were introduced.

Cast steel KL was melted according to air-refining method in $10 \mathrm{~T}$ electric-arc furnace. The TZ1 chromium cast steel were remelted in $0,5 \mathrm{~T}$ electric-arc furnace.
In Table 1 the chemical analysis of obtained alloys is presented. Additionally, the chemical composition of CREUSABRO ${ }^{\circledR} 8000$ low-alloyed steel is presented. This material is characterised by high wear resistance and is given for comparison.

Table 1

Chemical composition of studied low-alloyed and chromium cast steels, together with comparison material, in \% wt.

\begin{tabular}{|c|c|c|c|c|c|c|c|c|c|c|c|c|c|}
\hline No & Melt & $\mathbf{C}$ & Mn & $\mathbf{S i}$ & $\mathbf{P}$ & $\mathbf{S}$ & $\mathrm{Cr}$ & $\mathbf{N i}$ & Mo & $\mathbf{V}$ & $\mathbf{C u}$ & Al & $\mathbf{T i}$ \\
\hline \multicolumn{14}{|c|}{ low-alloyed cast steels } \\
\hline 1 & $\mathrm{~K} 4$ & 0,23 & 0,74 & 0,93 & 0,014 & 0,002 & 0,62 & 1,34 & 0,78 & 0,041 & 0,51 & 0,005 & 0,014 \\
\hline 2 & K6 & 0,22 & 0,55 & 0,56 & 0,008 & 0,007 & 0,68 & 0,80 & 0,47 & 0,052 & 0,44 & 0,002 & 0,023 \\
\hline 3 & K7 & 0,24 & 0,58 & 0,95 & 0,011 & 0,006 & 1,25 & 2,83 & 0,48 & 0,075 & 0,19 & 0,010 & 0,028 \\
\hline 4 & KL & 0,23 & 0,85 & 0,58 & 0,013 & 0,006 & 0,81 & 1,13 & 0,31 & 0,060 & 0,08 & 0,032 & 0,040 \\
\hline \multicolumn{14}{|c|}{ chromium cast steels } \\
\hline 5 & T6 & 0,56 & 0,51 & 0,58 & 0,015 & 0,011 & 18,30 & 1,69 & 0,80 & 0,320 & 0,18 & 0,006 & 0,120 \\
\hline 6 & T7 & 0,45 & 0,42 & 0,72 & 0,022 & 0,007 & 11,90 & 1,40 & 0,76 & 0,470 & 0,20 & 0,009 & 0,120 \\
\hline 7 & $\mathrm{~T} 8$ & 0,53 & 0,45 & 0,77 & 0,024 & 0,010 & 6,11 & 1,59 & 0,74 & 0,300 & 0,21 & 0,008 & 0,160 \\
\hline 8 & TZ1 & 0,63 & 0,46 & 0,83 & 0,024 & 0,011 & 17,90 & 3,00 & 0,62 & 0,042 & 0,12 & 0,070 & 0,033 \\
\hline \multicolumn{14}{|c|}{ CREUSABRO $^{\mathbb{R}} 8000$ steel } \\
\hline 9 & $\mathrm{C} 8$ & 0,24 & 1,16 & 0,71 & 0,008 & 0,003 & 0,65 & 0,26 & 0,30 & 0,009 & 0,15 & 0,036 & 0,044 \\
\hline
\end{tabular}

Specimens for abrasive wear were cut out from a sample billet. In Fig. 1 the sample casting after knocking-out is shown. The position of specimens for abrasive test is marked.

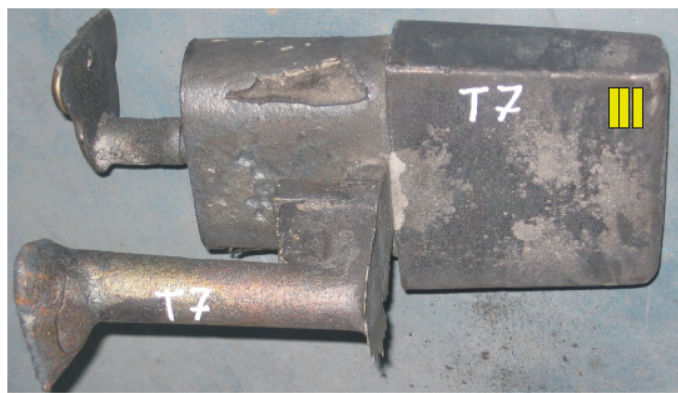

Fig. 1. Sample casting after knocking-out with marked position of specimens for abrasive tests

Low-alloyed and chromium cast steel were subjected to heat treatment operations, consisting of quenching and tempering. The heat treatment parameters together with hardness obtained after the operation are shown in Table 2.

Measurements of abrasive wear were performed on Tribotester 3 POD stand, which was designed and built in Department of Foundry of Silesian University of Technology [9]. The method applied is derived from the pin-on-disc group in which the rodlike specimen is pushed toward the rotating disc plate causing the abrasive wear. In Tribotester 3-POD, three specimens are mounted, at the same time, in the independently rotating holder. Fig. 2 shows the scheme of the method applied, the specimen and a general view of the apparatus. During the test one of the mounted specimens is the reference material. Each of the specimen can be loaded with different feed force. The disc plate is usually covered with abrasive paper with known grit size and type of abrasive material
Table 2.

Heat treatment parameters and hardness of cast steel samples after the operation

\begin{tabular}{|c|c|c|c|}
\hline Description & $\begin{array}{c}\text { Quenching } \\
\text { Temp./medium }\end{array}$ & $\begin{array}{c}\text { Tempering } \\
\text { Temp./medium }\end{array}$ & $\begin{array}{c}\text { Hardness } \\
\text { HRC } \\
\end{array}$ \\
\hline $\mathrm{K} 4 / 250$ & \multirow{8}{*}{$920^{\circ} \mathrm{C} /$ water } & \multirow{4}{*}{$250^{\circ} \mathrm{C} /$ air } & 43 \\
\hline K6/250 & & & 45 \\
\hline K7/250 & & & 46 \\
\hline $\mathrm{KL} / 250$ & & & 43 \\
\hline $\mathrm{K} 4 / 550$ & & \multirow{4}{*}{$550^{\circ} \mathrm{C} /$ air } & 32 \\
\hline K6/550 & & & 29 \\
\hline $\mathrm{K} 7 / 550$ & & & 36 \\
\hline $\mathrm{KL} / 550$ & & & 31 \\
\hline T6/250 & \multirow{8}{*}{$950^{\circ} \mathrm{C} /$ air } & \multirow{4}{*}{$250^{\circ} \mathrm{C} / \mathrm{air}$} & 49 \\
\hline $\mathrm{T} 7 / 250$ & & & 50 \\
\hline $\mathrm{T} 8 / 250$ & & & 52 \\
\hline $\mathrm{TZ1} / 250$ & & & 52 \\
\hline $\mathrm{T} 6 / 550$ & & \multirow{4}{*}{$550^{\circ} \mathrm{C} /$ air } & 40 \\
\hline $\mathrm{T} 7 / 550$ & & & 40 \\
\hline $\mathrm{T} 8 / 550$ & & & 43 \\
\hline $\mathrm{TZ1} / 550$ & & & 42 \\
\hline $\mathrm{C} 8$ & \multicolumn{2}{|c|}{ in delivered state } & 45 \\
\hline
\end{tabular}

The direction of disc plate rotation is opposite to the rotation of the mounting specimen holder. Controlled parameters of the method include: rotational speed of the disc plate, the holder, the feed force of the specimens, type of the abrasive plate, and time of the experiment.

During presented studies following conditions were applied:

- $\quad$ type of the abrasive plate: C120 abrasive paper (SiC),

- rotational speed of the disc: $100 \frac{1}{\mathrm{~min}}$

- rotational speed of the holder: $400 \frac{1}{\mathrm{~min}}$

- feed force of a single specimen: $220 \mathrm{G}$, 
- $\quad$ time of the test: $50 \mathrm{~min}$.,

- $\quad$ dry conditions of abrasion.
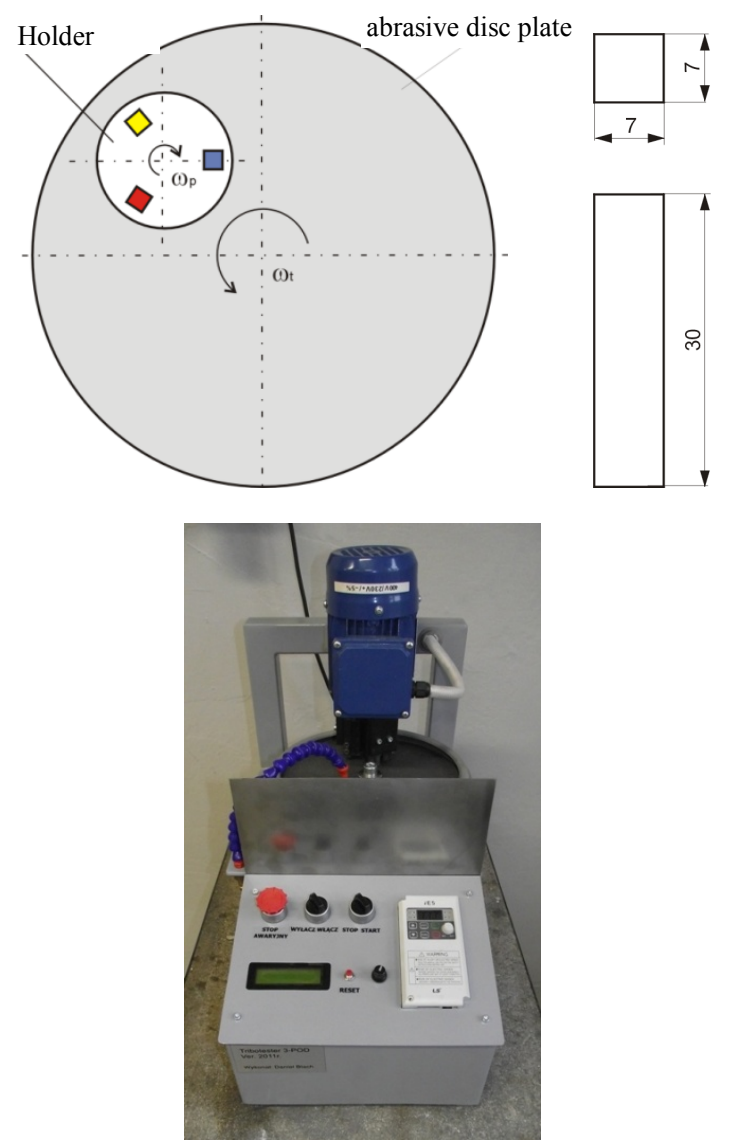

Fig. 2. Scheme of the method used, the specimen and general view of the Tribotester 3-POD apparatus

\section{Abrasive wear of low-alloyed cast steel}

In Fig. 3 the weight loss of studied cast steel specimens was shown according to applied measurement cycles. Strong influence of heat treatment operation can be observed fo low-alloyed cast steel, especially in case of tempering temperature. Elevated temperature of tempering causes significantly higher weight loss than in case of low tempering. In Fig. 4 the relative wear of individual specimens. Tempering at low temperature of lowalloyed cast steel provides relatively low abrasive wear and the relative wear index (Iwz = weight loss of a specimen/weight loss of a reference ratio) yields a value less than 1 .
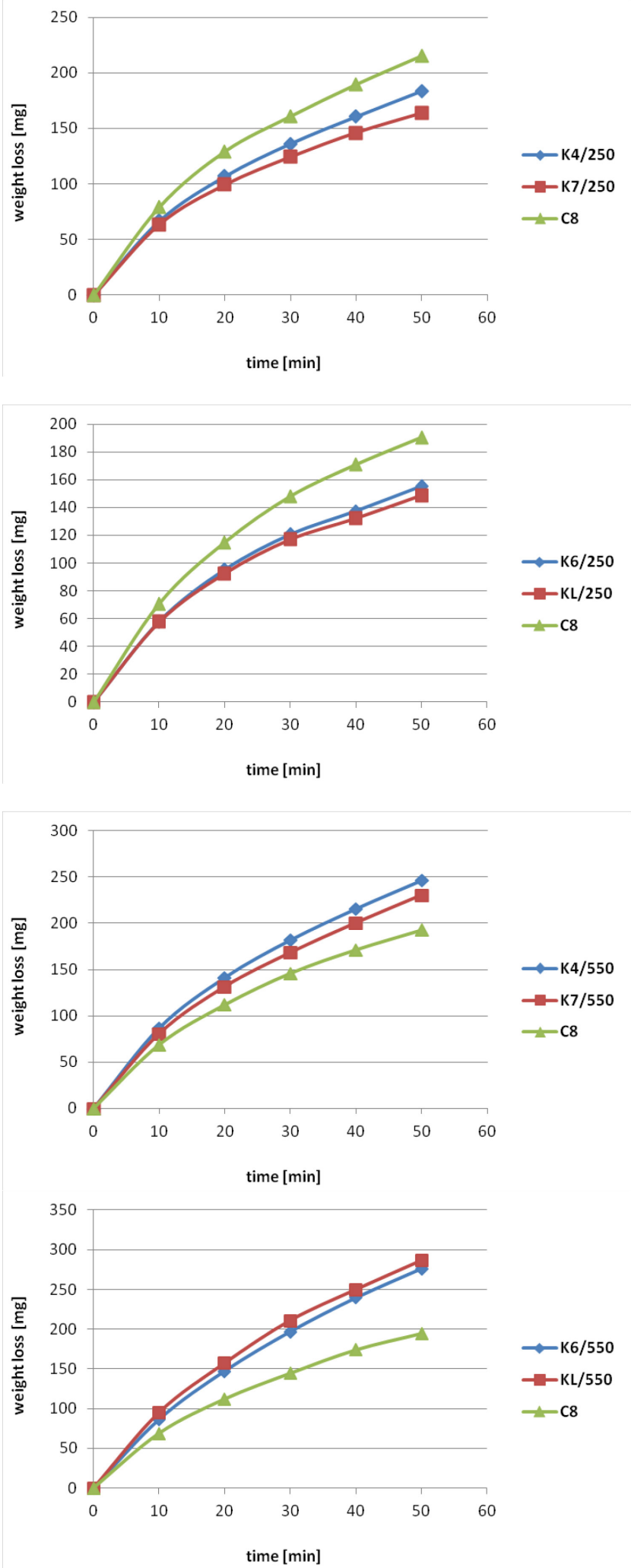

Fig. 3. Weight loss of specimens in measuring cycle for lowalloyed cast steel 


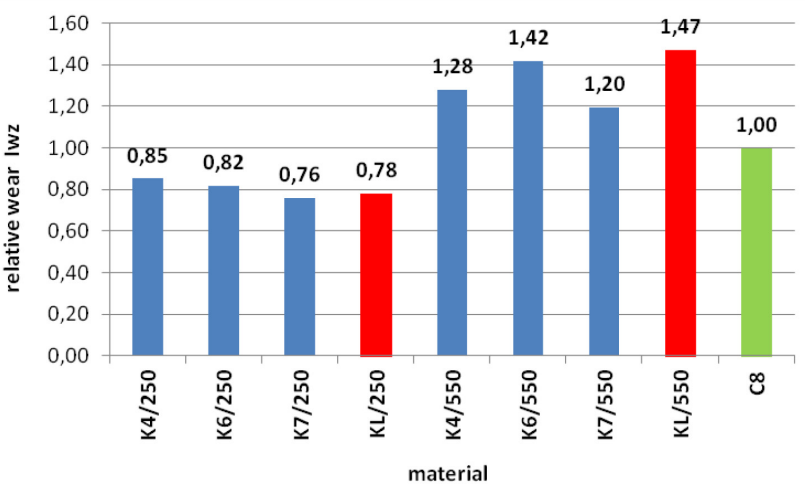

Fig. 4. Relative wear index for studied low-alloyed cast steel

\section{Abrasive wear of chromium cast steel}

In Fig. 5 the weight loss of studied chromium cast steel specimens was shown according to applied measurement cycles. Regardless of the heat treatment operations all of the specimens have shown lower weight loss than the reference material. Such state can be explained by occurrence of carbide phases in the structure of chromium cast steel, mainly at the grain boundaries. Also the hardness of these alloys after low tempering is higher than the hardness of the reference steel. In Fig. 6 the relative wear of individual specimens is shown. The relative wear index Iwz in all cases yields a value less than 1 .
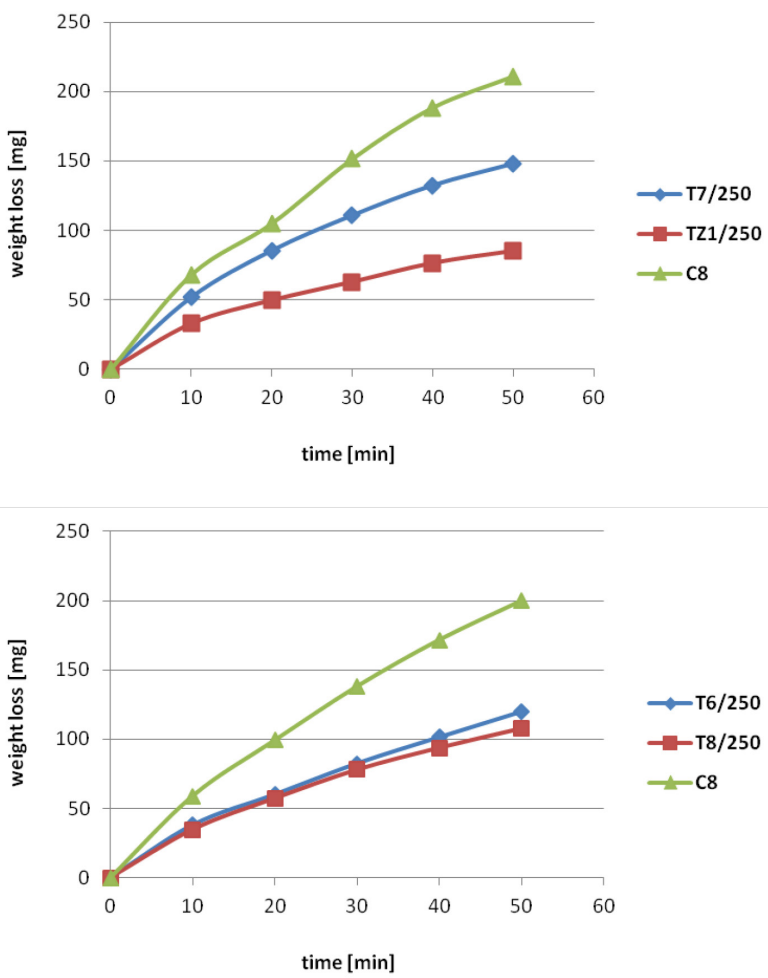
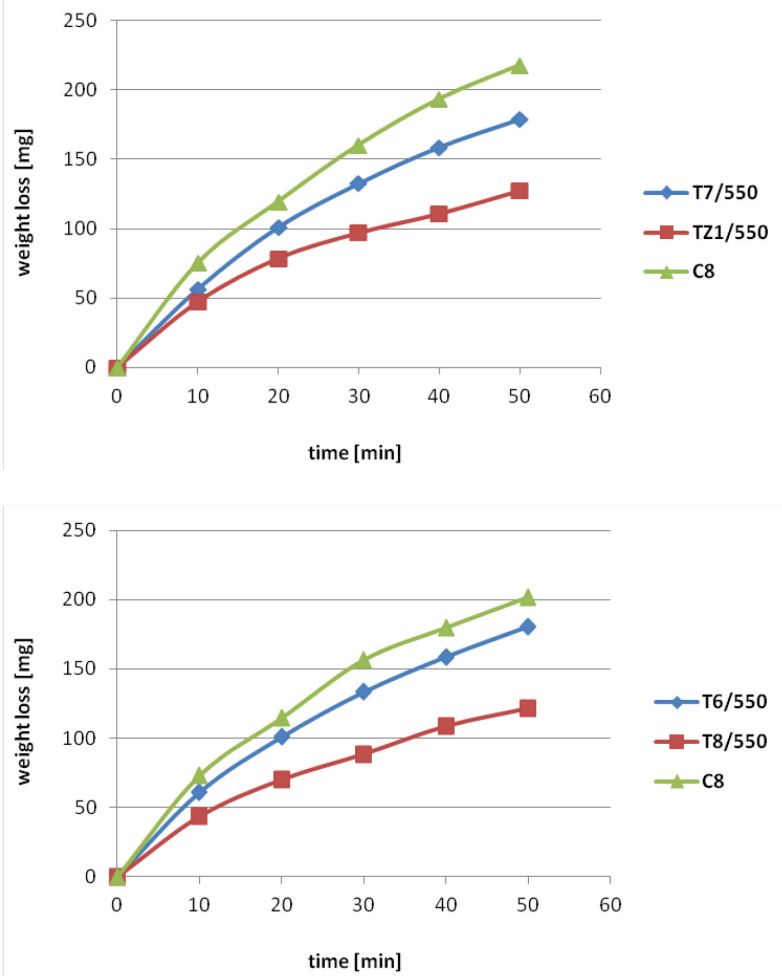

Fig. 5. Weight loss of specimens in measuring cycle for chromium cast steel

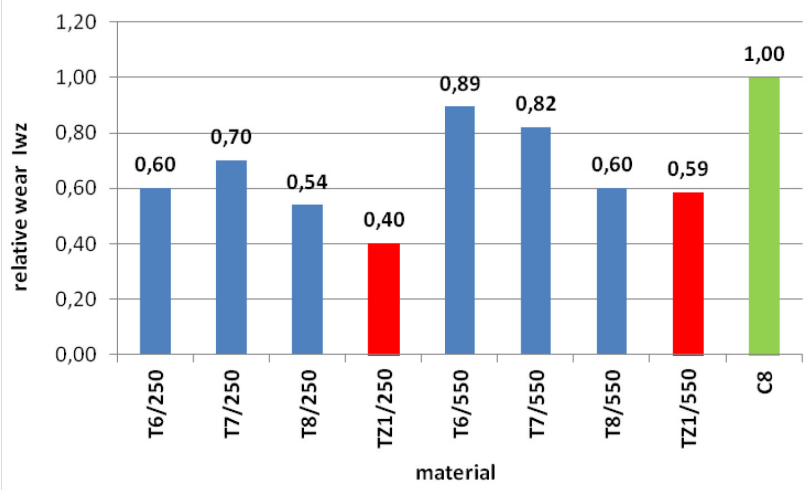

Fig. 6. Relative wear index for studied chromium cast steel

\section{Summary and conclusions}

Abrasive wear of studied low-alloyed cast steel is strongly dependent on the parameters of heat treatment operations. Application of tempering, which provides the resulting mechanical properties must be carefully selected to obtain optimum wear resistance. Higher values of temperature during tempering enables high plasticity, simultaneously deteriorates the abrasive wear resistance. In Fig. 7 the influence of hardness on relative abrasive wear of studied low-alloyed cast steel is presented. A typical structure of these alloys after quenching 
consists of low-tempered martensite and ferrite (Fig. 8a). After high tempering the structure consists of high-tempered martensite (sorbite) and ferrite (Fig. 8b).

In case of chromium cast steel the relative abrasive wear for all studied specimens yields value less than 1, regardless of alloy hardness. The most probable cause of such state is the occurrence of carbide eutectic phase in the alloy structure, which improves the wear resistance. The quantity of carbide phase ranges from $0,25 \%$ for cast steel containing $6 \%$ of $\mathrm{Cr}$ up to $1,5 \%$ for cast steel with $17 \% \mathrm{Cr}$. The structure of this cast steel after quenching and low tempering three main components are observed: martensite, retained austenite and carbide phases mainly occurring at the grain boundaries.

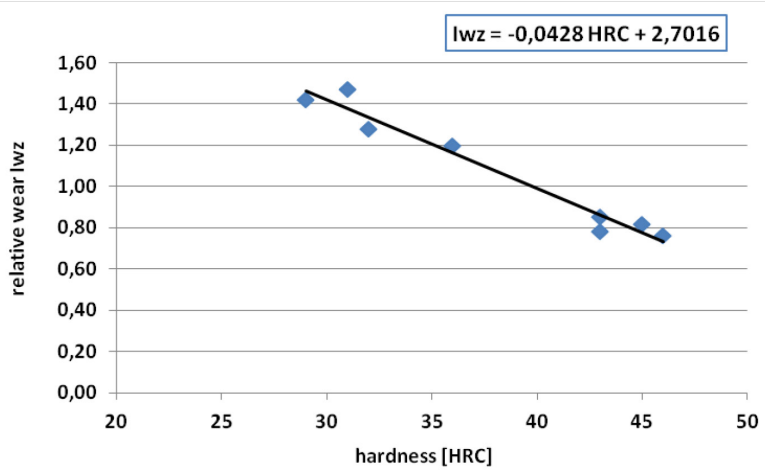

Fig.7. Relative wear index in function of low-alloyed cast steel hardness

a)

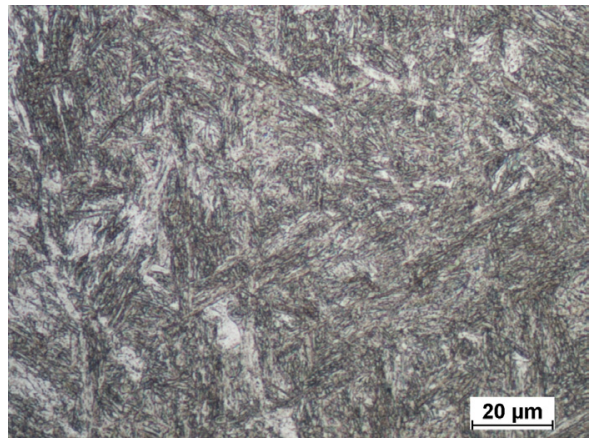

b)

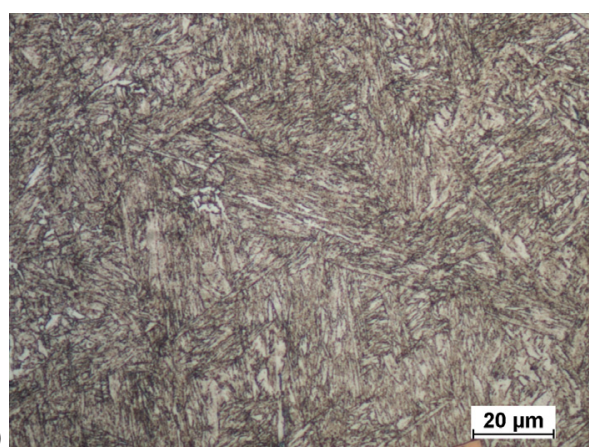

Fig. 8. Structure of low-alloyed cast steel KL: a) after quenching and low tempering; b) after quenching and high tempering, Nital etched

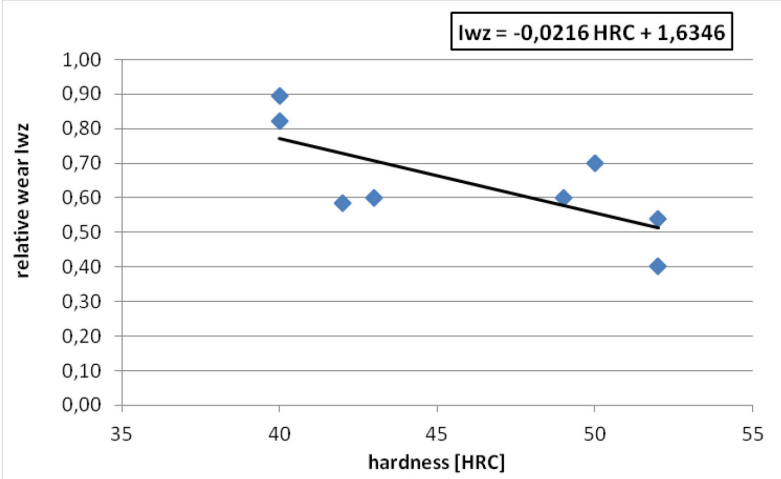

Fig. 9. Relative wear index in function of chromium cast steel hardness

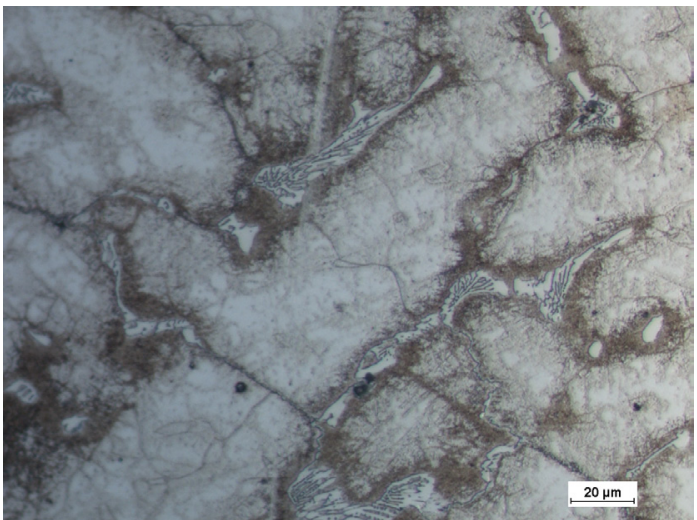

Fig. 10. Structure of chromium cast steel TZ1 after quenching and low tempering, $\mathrm{FeCl}_{3}$ etched

Based on conducted studies on abrasive wear of low-alloyed and chromium cast steels following conclusions were formulated:

\section{Low-alloyed cast steel:}

1. Low temperature of tempering after quenching in water enables obtainment of high abrasive wear resistance.

2. In case of necessity for high plasticity of the alloy the high tempering need to be applied, what causes deterioration of wear resistance.

\section{Chromium cast steel}

1. Even small amount of carbide phase in the alloy structure increases the abrasive wear resistance of the alloy.

2 . In case of elements which working conditions include only abrasion it is recommended to use alloys in which the chromium content does not exceed $6 \%$ wt., what is sufficient to obtain carbide phases favourably distributed in the alloy structure.

3 . In case of complex conditions, consisting of abrasive and corrosive wear it is recommended to apply cast steel in which the chromium content exceeds $12 \%$ wt., which ensures proper corrosion and wear resistance. 


\section{Acknowledgement}

This work was prepared under the Research and Development Project N R507 0054 10, financed by Polish Ministry of Science and Higher Learning.

\section{References}

[1] Kniaginin, G. (1972). Cast steel. Metallurgy and Founding. Publisher Ślask, Katowice (in Polish).

[2] Sakwa, W., Jura, S., Sakwa, J. (1980). Wear Resistance Iron Alloys. Part II Cast Steel. Publisher ZG STOP, Kraków (in Polish).

[3] Kondracki, M., Studnicki, A, Szajnar, J. (2013). Corrosion Studies of High-Chromium Cast Steels applied for Heavy Machinery Parts, Ochrona przed Korozją (Corrosion Protection) 12. 574-579 (in Polish).

[4] Kondracki, M., Studnicki, A, Szajnar, J. (2014). Influence of Carburising and Heat Treatment Operation on Selective Corrosion of Chromium Cast Steels, Ochrona przed Korozją (Corrosion Protection) 5, 174-178

[5] Dobrzański, L.A. (2004). Metal Engineering Materials. Publisher WNT Warszawa (in Polish).
[6] Głownia, J. (2002): Castings from Alloyed Cast Steel, Application. Publisher Fotobit, Kraków (in Polish).

[7] PN-88/H-83160 Standard: Abrasive Resistant Cast Steel (in Polish).

[8] PN-87/H-83156 Standard: Constructional Cast Steel (in Polish).

[9] PN-EN 10340 Standard: Cast Steel Castings for Construction Application (in Polish).

[10] PN-EN 10293 Standard: Cast Steel Castings for General Purposes (in Polish).

[11] Studnicki, A., Kondracki, M. \& Szajnar, J. (2012). Primary Crystallization of High Chromium Cast Steel in Metastable Conditions, Archives of Foundry Engineering, vol.12, Special Issue 2. 59-66

[12] Studnicki, A., Kondracki, M., Szajnar, J. \& Wróbel, T. (2013). Crystallization of Low-Alloyed Construction Cast Steel Modified with $\mathrm{V}$ and Ti. Archives of Foundry Engineering, 13 (3). 92-96

[13] Szajnar, J., Studnicki, A, Głownia, J., Kondracki, M., Suchoń, J. \& Wróbel, T. (2013). Technological Aspects of Low-Alloyed Cast Steel Massive Casting Manufacturing, Archives of Foundry Engineering. 13. (4). 97-102

[14] Studnicki, A., Kondracki, M., Szajnar, J. (2013). Primary Crystallization of Chromium Cast Steel in Metastable Conditions, Metal 2013; Conference Proceedings, p. 669-675 